[18] Liu, J. A., Cheung, M. (2016). Neural crest stem cells and their potential therapeutic applications. Developmental Biology, 419 (2), 199-216. doi: http://doi.org/10.1016/j.ydbio.2016.09.006

[19] Mikheytseva, I. N. (2014). Glaucoma modeling and adrenal stress. The Journal of Clinical and Experimental Medical Research, 2 (4), 427-437. Available at: http://essuir.sumdu.edu.ua/handle/123456789/38944

[20] Vasyliev, R. G. (2014). In vitro properties of neural crest-derived multipotent stem cells from a bulge region of whisker follicle. Biotechnologia Acta, 7 (4), 71-79. doi: http://doi.org/10.15407/biotech7.04.071

\title{
PREOPERATIVE ENDOBRONCHIAL SANITATION AS PREPARATION FOR THORACIC INTERVENTIONS
}

\author{
Vasiliy Kritsak \\ Kritsakvv@gmail.com \\ Kateryna Ponomarova ${ }^{1}$ \\ eponkat@gmail.com \\ Dmitriy Minukhin \\ Department of surgery No. 1 \\ Kharkiv National Medical University \\ 4 Nauky ave., Kharkiv, Ukraine, 61022 \\ minukhindima@gmail.com \\ ${ }^{1}$ Department of Thoraco-Abdominal Surgery \\ V. T. Zaytsev Institute of General and Emergency Surgery of NAMS of Ukraine \\ 1 Balakireva entry, Kharkiv, Ukraine, 61018
}

\begin{abstract}
The aim - to study the effectiveness of endoscopic photodynamic therapy as a preoperative preparation of the tracheobronchial tree in patients with lung cancer.

Materials and methods. The study included 181 patients with II-III stage of lung's cancer. Diagnose of lung's cancer was confirmed with a morphologically and concomitant endobronchitis. During the preoperative preparation, we used a technique developed by us introducing into the tracheobronchial tree an aqueous solution of brilliant green at concentration of $0.04 \%$, followed by irradiation of this solution with laser radiation with the wavelength of $0.63 \mu \mathrm{m}$ (AFL-2 helium-neon laser) in an independent form and in combination with traditional anti-inflammatory therapy. Endoscopic endobronchial sanitation therapy was carried out by low-intensity radiation of the red part of the spectrum $(\lambda=0.63-0.66 \mu \mathrm{m})$ in a pulsed mode, with a power of $12 \mathrm{~mW}$.

Results. After 3-5 days of the start preoperative preparation and 1-2 sessions of endoscopic bronchosanation, the general state of patients was improved, the amount of sputum decreased and was changing from mucopurulent to mucous. To completely stop the clinical phenomena of endobronchitis, it was necessary to conduct 5-6 sessions of endoscopic photodynamic therapy according to our methodology, with the introduction of our method. In patients without pronounced clinical symptoms of concomitant chronic bronchitis, it was enough to complete only 3 sessions of bronchosanation.

Conclusion. Endoscopic photodynamic bronchosanation in the preoperative period in patients for correcting accompanying endobronchitis can significantly reduce or completely stop the clinical manifestations of endobronchitis in the shortest time and leads to a significant decrease in the number of endobronchial complications in surgical and combined treatment of lung cancer.
\end{abstract}

Keywords: preoperative preparation, endoscopic photodynamic therapy, complications. 


\section{Introduction}

In spite of improvement of surgical procedures and preoperative preparation, the immediate results of radical operations for lung tumors remain unsatisfactory. Postoperative complications take place in $5.0-37.5 \%$ of the operated patients [1,2].

The most serious and dangerous complications of surgical treatment of lung's cancer are failure of the bronchus stump; bronchial fistula with developing of empyema of pleural cavity; diffuse purulent endobronchitis $[3,4]$.

According to various authors, the presented complications make up 3.0-12.0\% in the general structure of postoperative outcomes $[5,6]$.

Postoperative mortality among patients with bronchial fistula is $21.0-30.0 \%$ of incidents [7, 8].

Patients with lung's cancer have difficult postoperative endobronchial complications. Moreover, they have big problems in treatment and the operation significantly worsen the quality of life of radically operated patients $[9,10]$. Conservative treatment of bronchial fistula can be successful only in the early stages of formation of the fistula, until the formation of a stable scar channel and his epithelization $[11,12]$.

The inflammatory process in the mucosa of the bronchial tree is usually accompanied by edema and hyperemia of mucous membrane, decrease of elasticity, contact bleeding and presence of the sputum in the lumen of bronchial tree. In this case, the drainage function of the ciliated epithelium gets worse, with microcirculation impairments and accumulation of thick bronchial secretions $[13,14]$.

It is generally recognized, that the state of the bronchial epithelium in the preoperative period in patients with cancer is crucial to regenerative processes in the bronchus stump [14, 15]. That is why, success in the treatment of chronic bronchitis is determined by the search for new methods of therapy, including those, whose action is aimed at stimulating regenerative processes $[16,17]$.

One of them is the low-intensity laser irradiation method, which is widely used in general clinical practice $[18,19]$. However, in thoracic surgery its use restrained and cautious, because the mechanism of action and effect on the tumor cells are not fully understood [20, 21].

A number of experimental and clinical studies have shown, that low-intensity laser radiation of the red part of the spectrum $(\lambda=0.63-0.66 \mu \mathrm{m})$ does not have only pronounced anti-inflammatory and stimulating tissue regeneration effect, but also does not stimulate tumor growth $[22,23]$.

However, in the available literature there are practically no works devoted to the use of photodynamic therapy as a method of preoperative preparation of the bronchial tree and treatment of postoperative endobronchial complications in patients after thoracic interventions [24, 25].

The aim of the research - study of the effectiveness of endoscopic photodynamic therapy as a preoperative preparation of the tracheobronchial tree in patients with lung cancer.

\section{Materials and methods}

The study was conducted from 2015 to 2019 years and included 181 patients with II-III stage of lung cancer, who treatment was in department of thoraco-abdominal surgery of SU «V. T. Zaytsev Institute of General and Emergency Surgery of NAMS of Ukraine». Diagnose of lung cancer was confirmed with a morphologically and concomitant endobronchitis.

The authors declare that all the procedures and experiments of this study respect the ethical standards in the Helsinki Declaration of 1975, as revised in 2008(5), as well as the national law. Informed consent to participate in the study was discussed and signed by all study participants.

In the preoperative period, all patients were divided into III representative groups: I group 63 patients, who received endoscopic photodynamic therapy in the preoperative period; II group 60 patients, who received complex treatment which included endoscopic laser therapy in combination with traditional anti-inflammatory therapy; III group - 58 patients, who received in the preoperative period only traditional anti-inflammatory therapy.

The studied groups are equivalent and comparable in terms of basic prognostic criteria: sex, age, stage of cancer and localization of the tumor process, as well as by the degree of severity of 
clinical, endoscopic signs of concomitant endobronchitis and the composition of the microflora of the bronchial tree.

During the preoperative preparation, we used a technique developed by us introducing into the tracheobronchial tree an aqueous solution of brilliant green at concentration of $0.04 \%$, followed by irradiation of this solution with laser radiation with the wavelength of $0.63 \mu \mathrm{m}$ (AFL-2 helium-neon laser) in an independent form and in combination with traditional anti-inflammatory therapy.

Endoscopic endobronchial sanitation therapy was carried out by low-intensity radiation of the red part of the spectrum $(\lambda=0.63-0.66 \mu \mathrm{m})$ in a pulsed mode, with a power of $12 \mathrm{~mW}$. Endoscopic endobronchial sanitation included a look at the trachea, bifurcation, head, lobar, segmental and subsegmental bronchial. We used device company Pentax (Japan). Sessions were carried out every other day, patients received 3-6 sessions of bronchosanation, which included - direct reorganization of the bronchial tree and laser irradiation in the indicated mode.

The complex of traditional preoperative preparation in the comparison group was consisting of: prescribing broad-spectrum antibiotics, which were taking into account the sensitivity of the microflora of the bronchial tree; bronchodilators; antitussive drugs; inhalation of alkaline solutions; oxygen therapy and respiratory gymnastics.

In the group of patients, who received comprehensive treatment for concomitant chronic endobronchitis, traditional anti-inflammatory treatment was performed as preoperative preparation according to the above scheme in combination with endoscopic laser therapy.

\section{Results}

For a fairly short period, it is possible to conduct an adequate highly effective preoperative preparation of the tracheobronchial tree.

In group I of patients, who received only endoscopic laser therapy, before the study a cough was in $55(87.3 \%),(\mathrm{p}<0.05)$, dyspnea $-40(63.4 \%),(\mathrm{p}<0.05)$. After completion of the preoperative preparation course (average 5-6 sessions), the cough persisted in $9(14.2 \%),(\mathrm{p}<0.05)$ patients, dyspnea $-4(6.3 \%),(p<0.05)$ cases. In group II, before the start of treatment, cough was observed in $58(96.6 \%),(\mathrm{p}<0.05)$ dyspnea $-38(63.3 \%),(\mathrm{p}<0.05)$ patients. After treatment, cough persisted in $5(8.3 \%),(\mathrm{p}<0.05)$ patients, dyspnea $-4(6.6 \%),(\mathrm{p}<0,05)$. In comparison group (III), cough was noted in $45(77.6 \%),(\mathrm{p}<0.05)$, dyspnea in $38(65.5 \%),(\mathrm{p}<0,05)$. After the preoperative preparation, cough $-20(34.5 \%)(\mathrm{p}<0,05)$ patients, dyspnea $-18(31.0 \%),(\mathrm{p}<0.05)$. The differences in the groups are statistically significant $(\mathrm{p}<0.05)$.

At the end of the preoperative preparation course, we were noted significant changes in the endoscopic picture of the bronchial tree. In I group hyperemia of the bronchial mucosa persisted only in $5(7.9 \%)$, edema of the bronchial mucosa $-2(3.3 \%)$, sputum in the lumen of the bronchial tree $-3(4.7 \%)$ cases. In the II group of combined preoperative preparation, the results of the treatment are more effective: no edema of the mucous membrane; sputum in the lumen of the bronchial tree - 1 (1.6\%); hyperemia of the mucous membrane - 2 (3.3\%) cases. When we were conducting preoperative preparation using only anti-inflammatory therapy (III group), it was not possible to completely stop the signs of inflammation, only to reduce their number: hyperemia of the bronchial mucosa - 16 (27.6 \%) cases; edema of the mucous membrane - $12(20.6 \%)$; sputum in the lumen of the bronchial tree $-14(24.1 \%)$ cases. The differences between the main and control groups are statistically significant $(\mathrm{p}<0.05)$ (Table 1).

Table 1

Paraclinical indicators after preoperative preparation

\begin{tabular}{ccccc}
\hline Data & I group & II group & III group & p \\
\hline Cough & $9(14.2 \%)$ & $5(8.3 \%)$ & $20(34.5 \%)$ & \\
Dyspnea & $4(6.3 \%)$ & $5(8.3 \%)$ & $18(31.0 \%)$ & \\
Hyperemia of the bronchial mucosa & $5(7.9 \%)$ & $2(3.3 \%)$ & $16(27.6 \%$ & $\mathrm{p}<0.05$ \\
Edema of the bronchial mucosa & $2(3.3 \%)$ & 0 & $12(20.6 \%)$ & \\
Sputum in the lumen of the bronchial tree & $3(4.7 \%)$ & $1(1.6 \%)$ & $14(24.1 \%)$ &
\end{tabular}


When we were analyzing the nature of pathogenic microflora after preoperative preparation (Staphylococcus aureus, Streptococcus pneumonia, Echerichia coli) we founded microflora in the lumen of the bronchial tree: I group - in $8 \pm 1.2$ patients; II group $-8 \pm 0.9$; III group - in $31 \pm 1.3$. The difference is statistically significant $(\mathrm{p}>0.05)$.

Another objective method for assessing the effectiveness of preoperative preparation was determined the rate of mucociliary clearance (MCC), since a long inflammatory process and results, which significant decrease in the drainage function of the bronchi. Used drugs that make up the complex of traditional anti-inflammatory therapy cause only a little increase in mucociliary clearance up to $30.0 \pm 4.1 \%$. After preoperative preparation, the using endoscopic photodynamic bronchosanation, it is showed, that the MCC's speed has increased and was equal to $47 \pm 3.7 \%$. This corresponds to the normal MCC speed indicator.

Microscopic examination of histological preparations of the bronchial mucosa showed that after preoperative endoscopic laser therapy using photodynamic therapy (I group), mucosal edema and leukocytes were completely absent. In II group edema was in $4 \pm 0.7$ patients, leukocytes 7 \pm 2.3 . In III group, $14 \pm 1.1$ patients had edema, leukocytes $-19 \pm 1.7(\mathrm{p}<0.05)$.

We were noted metaplasia of bronchial epithelium, in $1 \pm 0.3$ patients of I group and in $1 \pm 0.1$ of II group. In the control group (III), epithelial metaplasia is characterized by an inflammatory process in the bronchial system - in $27(46.5 \%)$ patients $(\mathrm{p}<0.05)$.

Along with metaplasia of the bronchial mucosa, were determined dysplastic changes in bronchial epithelium of various degrees in a number of patients of the studied groups. In I group was noted decrease in the total number of bronchial epithelium dysplasia and persisted in $22(35.0 \%)$ patients, in group II - 25 (41.6 \%). In patients, who received traditional preoperative preparation (group III), dysplastic changes in the bronchial mucosa persisted in 43 (74.1\%) cases, and in more than half of the cases after treatment, the initial degree of dysplasia.

\section{Discussion}

The results indicate a quick and effective relief of all signs of concomitant chronic bronchitis in patients of the I and II groups, due to which microcirculation improves, the energy potential of cells increases, and regeneration processes in the mucous membranes normalize.

After completing the course of preoperative preparation using various methods of rehabilitation of the tracheobronchial tree, were noted significant changes in the inflammatory process in the bronchial tree, according to a number of clinical, laboratory, endoscopic and morphological criteria [12].

There was an improvement in general condition of the patient and a decrease in the main clinical symptoms of concomitant chronic bronchitis in all the studied groups [17]. At the same time, already 3-5 days after the start of preoperative preparation, after 1-2 sessions of endoscopic bronchosanation in patients, their general state of health improved, the amount of expectorated sputum decreased and its character changed from mucopurulent to mucous. In patients of the comparison group, these changes in the clinical manifestations of bronchitis were recorded at a later date after 10-14 days from the start of treatment [23].

To completely stop the clinical phenomena of endobronchitis, it was necessary to carry out from 5 to 6 sessions of endoscopic photodynamic therapy according to our methodology, with the introduction of an aqueous solution of brilliant green dye at a concentration of $0.04 \%$ into the tracheobronchial tree, followed by irradiation of this solution with laser radiation with a wavelength of 0,63 microns (AFL-2 helium-neon laser), output power of the fiber is $12 \mathrm{~mW}$. In patients without pronounced clinical symptoms of concomitant chronic bronchitis, it was sufficient to complete only 3 sessions of bronchosanation using the proposed technique.

In the I group of patients after surgical complications in the form of bronchial fistulas or the development of diffuse endobronchitis was not observed. In the II group of patients (Fig. 1), who received a photodynamic bronchodication in combination with traditional preoperative preparation, endobronchial complications were recorded only in $5(6.6 \%)$ cases of cases: bronchial fistulas $-3(5.0 \%)$, diffuse endobronchitis - 1 (1.6\%) cases. Complications in the III group of patients received anti-inflammatory therapy without additional bronchial debridement in 
9 (15.5\%): bronchial fistula - $6(10.3 \%)$ patients; endobronchitis II-III degree of severity $3(5.2 \%)$. The difference is statistically significant $(\mathrm{p}<0.05)$.

In the series of patients after pneumonectomy, the proportion of BPF reported in each study ranged from 0 to $17.0 \%$. In the pooled population, the proportion of BPF was $4.0 \%$ [25].

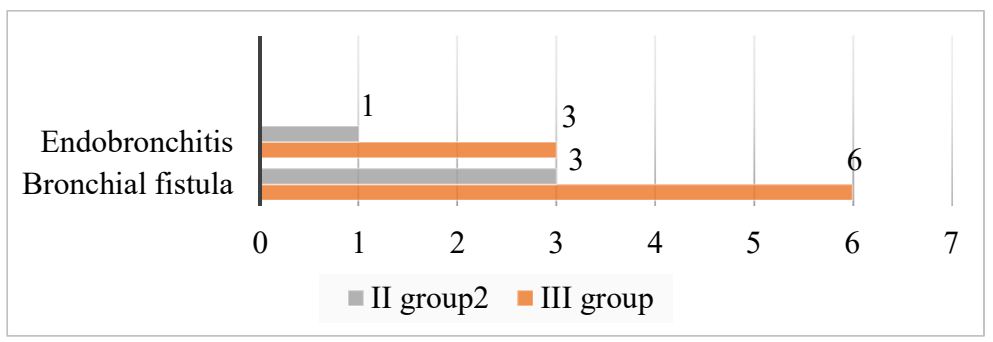

Fig. 1. Complications in the postoperative period

Study limitations. The use of drug therapy contributes to decrease of inflammatory processes, which improves the postoperative period, however, to realize the full effect of the treatment, it need has longer period and additional prescription of physiotherapeutic methods of treatment, which are absolutely contraindicated for cancer patients. The difference in better effect in group II, compared with group I of patients who received endoscopic bronchosanation in an independent form, is probably associated with a short use of traditional medicines for 10-14 days.

Prospects for the further research. Since the use of endoscopic bronchosanation and the combination of this method with conservative therapy can significantly improve treatment results, we plan to develop an algorithm that will reduce the number of perioperative costs and complications.

\section{Conclusions}

The using of endoscopic photodynamic bronchosanation in the preoperative period in patients for correcting accompanying endobronchitis in an independent form and in combination with traditional anti-inflammatory therapy, can significantly reduce or completely stop the clinical manifestations of concomitant endobronchitis in the shortest time and leads to a significant decrease in the number of endobronchial complications in surgical and combined treatment of lung's cancer, compared to the comparison group.

\section{Conflict of interests}

The authors declare that they have no conflicts of interest.

\section{References}

[1] Cao, C., Manganas, C., Ang, S. C., Peeceeyen, S., Yan, T. D. (2012). Video-assisted thoracic surgery versus open thoracotomy for non-small cell lung cancer: a meta-analysis of propensity score-matched patients. Interactive CardioVascular and Thoracic Surgery, 16 (3), 244-249. doi: http://doi.org/10.1093/icvts/ivs472

[2] Pagès, P.-B., Mordant, P., Renaud, S., Brouchet, L., Thomas, P.-A., Dahan, M., Bernard, A. (2017). Sleeve lobectomy may provide better outcomes than pneumonectomy for non-small cell lung cancer. A decade in a nationwide study. The Journal of Thoracic and Cardiovascular Surgery, 153 (1), 184-195.e3. doi: http://doi.org/10.1016/j.jtcvs.2016.09.060

[3] Maurizi, G., D’Andrilli, A., Anile, M., Ciccone, A. M., Ibrahim, M., Venuta, F., Rendina, E. A. (2013). Sleeve Lobectomy Compared with Pneumonectomy after Induction Therapy for Non-Small-Cell Lung Cancer. Journal of Thoracic Oncology, 8 (5), 637-643. doi: http://doi.org/10.1097/jto.0b013e318286d145

[4] Ma, Q.-L., Guo, Y.-Q., Shi, B., Tian, Y.-C., Song, Z.-Y., Liu, D.-R. (2016). For non-small cell lung cancer with T3 (central) disease, sleeve lobectomy or pneumonectomy? Journal of Thoracic Disease, 8 (6), 1227-1233. doi: http://doi.org/10.21037/ jtd.2016.04.60

[5] Gonzalez, M., Litzistorf, Y., Krueger, T., Popeskou, S. G., Matzinger, O., Ris, H.-B. et. al. (2013). Impact of Induction Therapy on Airway Complications After Sleeve Lobectomy for Lung Cancer. The Annals of Thoracic Surgery, 96 (1), $247-252$. doi: http://doi.org/10.1016/j.athoracsur.2013.04.009 
[6] Iijima, Y., Hirotsu, Y., Amemiya, K., Higuchi, R., Nakagomi, T., Goto, T. et. al. (2019). Endotracheal or Endobronchial Metastasis of Lung Squamous Cell Carcinoma. Journal of Bronchology \& Interventional Pulmonology, 26 (4), e46-e50. doi: http:// doi.org/10.1097/lbr.0000000000000595

[7] Maurizi, G., Ciccone, A. M., Vanni, C., D’Andrilli, A., Ibrahim, M., Andreetti, C. et. al. (2018). Reimplantation of the upper lobe bronchus after lower sleeve lobectomy or bilobectomy: long-term results $\dagger$. European Journal of Cardio-Thoracic Surgery, 53 (6), 1180-1185. doi: http://doi.org/10.1093/ejcts/ezx494

[8] Blatter, J., Krueger, T., Ris, H.-B., Baeriswyl, M., Lovis, A., Zellweger, M. et. al. (2018). Complex Tracheocarinal Reconstructions Using Extrathoracic Muscle Flaps as Airway Substitutes. The Annals of Thoracic Surgery, 105 (5), 1492-1498. doi: http:// doi.org/10.1016/j.athoracsur.2018.01.021

[9] Storelli, E., Tutic, M., Kestenholz, P., Schneiter, D., Opitz, I., Hillinger, S., Weder, W. (2012). Sleeve resections with unprotected bronchial anastomoses are safe even after neoadjuvant therapy. European Journal of Cardio-Thoracic Surgery, 42 (1), 77-81. doi: http://doi.org/10.1093/ejcts/ezr291

[10] Hong, T. H., Cho, J. H., Shin, S., Kim, H. K., Choi, Y. S., Zo, J. I. et. al. (2018). Extended sleeve lobectomy for centrally located non-small-cell lung cancer: a 20-year single-centre experience†. European Journal of Cardio-Thoracic Surgery, 54 (1), 142-148. doi: http://doi.org/10.1093/ejcts/ezy011

[11] Hishida, T., Aokage, K., Yoshida, J., Miyoshi, T., Tsuboi, M. (2018). Extended bronchoplasty for locally advanced left lower lobe lung cancer: surgical technique and outcomes $\dagger$. Interactive CardioVascular and Thoracic Surgery, 27 (4), $602-605$. doi: http://doi.org/10.1093/icvts/ivy081

[12] Vannucci, J., Matricardi, A., Potenza, R., Ragusa, M., Puma, F., Cagini, L. (2018). Lobectomy with angioplasty: which is the best technique for pulmonary artery reconstruction? Journal of Thoracic Disease, 10 (S16), S1892-S1898. doi: http://doi.org/ 10.21037/jtd.2018.05.174

[13] Chen, H., Huang, L., Xu, G., Zheng, B., Zheng, W., Zhu, Y. et. al. (2016). Modified bronchial anastomosis in video-assisted thoracoscopic sleeve lobectomy: a report of 32 cases. Journal of Thoracic Disease, 8 (8), 2233-2240. doi: http://doi.org/10.21037/ jtd.2016.07.74

[14] Broderick, S. R., Patel, A. P., Crabtree, T. D., Bell, J. M., Morgansztern, D., Robinson, C. G. et. al. (2016). Pneumonectomy for Clinical Stage IIIA Non-Small Cell Lung Cancer: The Effect of Neoadjuvant Therapy. The Annals of Thoracic Surgery, 101 (2), 451-458. doi: http://doi.org/10.1016/j.athoracsur.2015.07.022

[15] Kim, A. W., Boffa, D. J., Wang, Z., Detterbeck, F. C. (2012). An analysis, systematic review, and meta-analysis of the perioperative mortality after neoadjuvant therapy and pneumonectomy for non-small cell lung cancer. The Journal of Thoracic and Cardiovascular Surgery, 143 (1), 55-63. doi: http://doi.org/10.1016/j.jtcvs.2011.09.002

[16] Aresu, G., Wu, L., Lin, L., Jiang, G., Jiang, L. (2016). The Shanghai Pulmonary Hospital subxiphoid approach for lobectomies. Journal of Visualized Surgery, 2, 135. doi: http://doi.org/10.21037/jovs.2016.07.09

[17] Weaver, H., Ali, J. M., Jiang, L., Yang, C., Wu, L., Jiang, G., Aresu, G. (2017). Uniportal subxiphoid video-assisted thoracoscopic approach for thymectomy: a case series. Journal of Visualized Surgery, 3, 169-169. doi: http://doi.org/10.21037/ jovs.2017.10.16

[18] Liu, H.-F., Gao, L., Liu, T., Yan-Jiang, Wang, H.-B. (2016). Comparison of acute phase reaction and postoperative stress in pigs undergoing video-assisted thoracoscopic versus thoracotomy pneumonectomy. Acta Veterinaria Scandinavica, 58 (1). doi: http://doi.org/10.1186/s13028-016-0256-x

[19] Di Maio, M., Perrone, F., Deschamps, C., Rocco, G. (2014). A meta-analysis of the impact of bronchial stump coverage on the risk of bronchopleural fistula after pneumonectomy. European Journal of Cardio-Thoracic Surgery, 48 (2), 196-200. doi: http:// doi.org/10.1093/ejcts/ezu381

[20] Maurizi, G., Ciccone, A. M., Vanni, C., D’Andrilli, A., Ibrahim, M., Andreetti, C. et. al. (2018). Reimplantation of the upper lobe bronchus after lower sleeve lobectomy or bilobectomy: long-term results $\dagger$. European Journal of Cardio-Thoracic Surgery, 53 (6), 1180-1185. doi: http://doi.org/10.1093/ejcts/ezx494

[21] Cusumano, G., Marra, A., Lococo, F., Margaritora, S., Siciliani, A., Maurizi, G. et. al. (2014). Is Sleeve Lobectomy Comparable in Terms of Short- and Long-Term Results With Pneumonectomy After Induction Therapy? A Multicenter Analysis. The Annals of Thoracic Surgery, 98 (3), 975-983. doi: http://doi.org/10.1016/j.athoracsur.2014.04.095

[22] Boyko, V. V., Krasnoyruzhsky, A. G., Kritsak, V. V. (2017). The choice of photosensitizer and parameters of light radiation for endoscopic endobronchial photodynamic therapy. International Medical Journal, 23, 28-32. Available at: http://nbuv.gov.ua/ UJRN/Mmzh_2017_23_2_7

[23] D’Andrilli, A., Maurizi, G., Andreetti, C., Ciccone, A. M., Ibrahim, M., Poggi, C. et. al. (2014). Pulmonary Artery Reconstruction With Pulmonary Vein Conduit for Lung Cancer: Medium-Term Results. The Annals of Thoracic Surgery, 98 (3), $990-995$. doi: http://doi.org/10.1016/j.athoracsur.2014.04.110 
[24] Nagayasu, T., Yamasaki, N., Tsuchiya, T., Matsumoto, K., Miyazaki, T., Hatachi, G. et. al. (2015). The evolution of bronchoplasty and broncho-angioplasty as treatments for lung cancer: evaluation of 30 years of data from a single institution. European Journal of Cardio-Thoracic Surgery, 49 (1), 300-306. doi: http://doi.org/10.1093/ejcts/ezv065

[25] Maurizi, G., Ibrahim, M., Andreetti, C., D’Andrilli, A., Ciccone, A. M., Pomes, L. M. et. al. (2014). Long-term results after resection of bronchial carcinoid tumour: evaluation of survival and prognostic factors. Interactive CardioVascular and Thoracic Surgery, 19 (2), 239-244. doi: http://doi.org/10.1093/icvts/ivu109

\title{
UTERINE FIBROIDS IMPACT ON FERTILITY AND PREGNANCY OUTCOME
}

\author{
Olena Doroha ${ }^{2}$ \\ Department of Obstetrics, Gynecology And Perinatology \\ Ukrainian State Institute of Reproductology ${ }^{1}$ \\ ztrololoz@i.ua \\ Mykola Iarotskyi \\ Medical director \\ Academic Medical Center \\ 5/14 Rohnedynska Str., Kyiv, Ukraine, 01004 \\ info@amcenter.com.ua \\ Iryna Iarotska \\ Department of Obstetrics, Gynecology and Perinatology ${ }^{1}$ \\ ir-nik@ukr.net \\ Liudmyla Semeniuk \\ Department of Reproductive Medicine and Surgery \\ Ukrainian Scientific and Practical Center for Endocrine Surgery, Transportation Endocrine \\ Organ and Tissues Ministry of Health of Ukraine \\ 13 A Klovsky Uzviz, Kyiv, Ukraine, 01021 \\ Semeniukliudmyla1@gmail.com \\ Olga Nikitina \\ ztrololoz@i.ua \\ ${ }^{1}$ Shupyk National Medical Academy of Postgraduate Education \\ 9 Dorohozhytska str., Kyiv, Ukraine, 04112 \\ ${ }^{2}$ State Scientific Institution "Scientific and Practical Center for Preventive and Clinical Medi- \\ cine" of the State Administration of Affairs \\ 5 Verkhnya str., Kyiv, Ukraine, 01014
}

\section{Abstract}

The clinical confirmation of the relationship between uterine leiomyoma and female infertility is of interest to scholars.

The aim of our research was to study obstetric history and the level of sex hormones in women of reproductive age with leiomyoma.

Materials and methods. The main group consisted of 90 women of reproductive age with uterine leiomyoma, the control group - 45 healthy women. Gynaecological and obstetric history, hormone content in peripheral blood and pelvic vessels (estradiol, progesterone) were analysed. Statistical processing of clinical material was performed using Microsoft Excel, Statistica 7.0, and Statistica 8.0 for Windows. 